\title{
Solitary Fibrous Tumor of Internal Jugular Vein: An Extremely Rare Entity with Review of Literature
}

\author{
Khemendra Kumar ${ }^{1} \quad$ Parveen Kumar ${ }^{1} \quad$ Mona Bhatia $^{1} \quad$ Amit Garg ${ }^{1}$ \\ 1Deparment of Radiology, Fortis Escorts Heart Institute, New Delhi, \\ India \\ Address for correspondence Khemendra Kumar, Department \\ of Radiology, Fortis Escorts Heart Institute, New Delhi, India \\ (e-mail: drkhem@gmail.com).
}

Indian J Radiol Imaging 2021;31:484-487.

\begin{abstract}
Keywords

- internal jugular vein

- solitary fibrous tumor

- vascular

Solitary fibrous tumor (SFT) is an unusual spindle cell neoplasm that commonly arises from pleura. In the last decade, multiple case reports have described its diverse occurrence in extrapleural locations involving almost every anatomic site. Intravascular SFT is extremely rare and has been reported in inferior vena cava and renal vein only, to the best of our knowledge. SFT of the internal jugular vein has never been reported. We present a case of a SFT arising from internal jugular vein with extraluminal exophytic component extending into supraclavicular fossa. It should also be considered as a differential diagnosis for neoplasm arising from the internal jugular vein.
\end{abstract}

\section{Introduction}

Solitary fibrous tumor (SFT) is a mesenchymal tumor and commonly arises from pleura. It was first described by Klemperer and Rabin in $1931 .{ }^{1}$ Although pleura is the most common site of origin, multiple case reports in the last decade have shown that this can arise from any part of the body. It is commonly seen in middle-aged individuals without any gender preference. It is usually benign but rarely can show local recurrence and metastasis. ${ }^{2}$ Surgical excision is the main treatment method; however, there is the role of chemotherapy and radiotherapy in unresectable and metastatic disease. Intravascular SFT is extremely rare with only two cases reported so far, one arising from inferior vena cava (IVC) and another arising from the right renal vein. Herein we present a case of SFT arising from right internal jugular vein that has not been reported previously.

\section{Case History}

A 45-year-old male presented with complaints of swelling over the face and neck predominantly on the right side, as well as right arm region with redness in the right eye. Physical examination revealed a dilated vein over the right neck and

published online July 27, 2021
DOI https://doi.org/ $10.1055 / \mathrm{s}-0041-1734352$ ISSN 0971-3026 chest area with fullness over the right supraclavicular fossa. Ultrasound color Doppler of right neck vessels revealed a large hypoechoic lesion in the right lower internal jugular vein showing minimal vascularity on color Doppler (-Fig. 1). A continuing exophytic component was seen extending into the right supraclavicular fossa with discontinuity in the venous wall. Confluence of the right internal jugular vein and the right subclavian vein was not clearly delineated. To assess the extent of lesion and status of remaining vessels, computed tomography (CT) venography was advised that revealed a heterogeneously enhancing mass lesion arising from the distal right internal jugular vein with intraluminal and eccentric extraluminal component extending into the right supraclavicular fossa. Nonenhancing filling defect suggestive of thrombus was seen in the remaining lumen of the right internal jugular vein, both brachiocephalic vein, and superior vena cava ( - Fig. 2). Contrast-enhanced magnetic resonance imaging (MRI) and MR venography showed an intensely enhancing mass lesion arising from the lateral wall of the distal right internal jugular vein with small intraluminal and large exophytic component ( - Fig. 3). Internal jugular vein was not displaced. Nonenhancing filling defect suggestive of thrombus was seen in the remaining lumen (c) 2021. Indian Radiological Association.

This is an open access article published by Thieme under the terms of the Creative Commons Attribution-NonDerivative-NonCommercial-License, permitting copying and reproduction so long as the original work is given appropriate credit. Contents may not be used for commercial purposes, or adapted, remixed, transformed or built upon. (https://creativecommons.org/licenses/by-nc-nd/4.0/).

Thieme Medical and Scientific Publishers Private Ltd. A-12, Second Floor, Sector -2, NOIDA -201301, India 


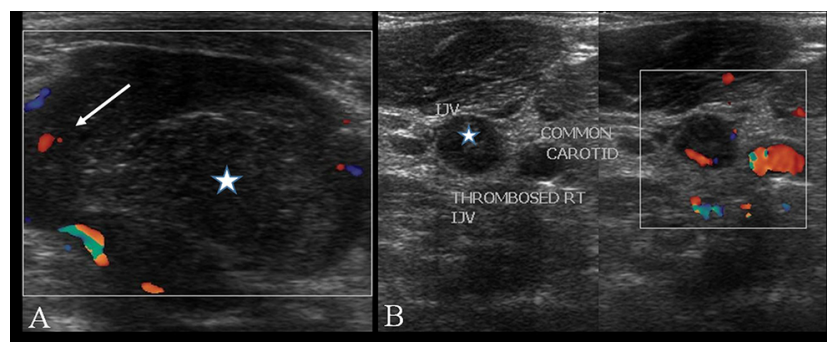

Fig. 1 Color Doppler examination of right neck vein. (A) An eccentric hypoechoic mass lesion (arrow) in the right internal jugular vein (IJV) showing vascularity on color Doppler. Heteroechoic thrombus is seen in the remaining lumen $\left({ }^{*}\right)$. (B) Cranial part of right IJV shows near-total luminal occlusion due to thrombus $\left({ }^{*}\right)$.

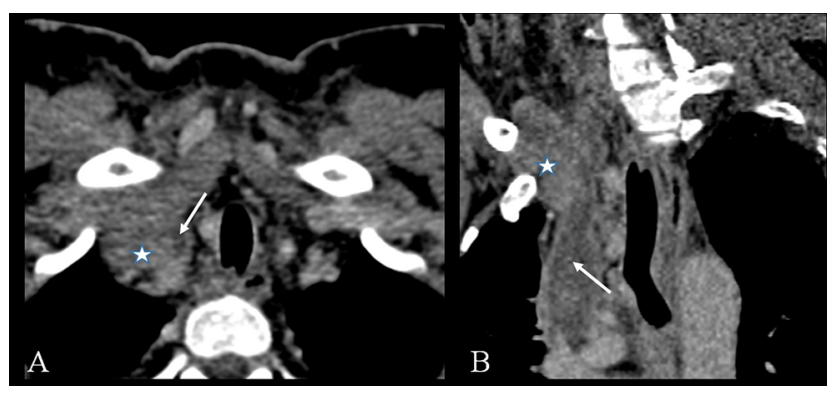

Fig. 2 Contrast-enhanced computed tomography with venography. Axial (A) and coronal (B) images show a heterogeneously enhancing mass lesion in the right internal jugular vein with small intraluminal and large exophytic component $\left({ }^{*}\right)$. Nonenhancing thrombus is seen in the rest of the compressed lumen and extending into the superior vena cava (white arrow).

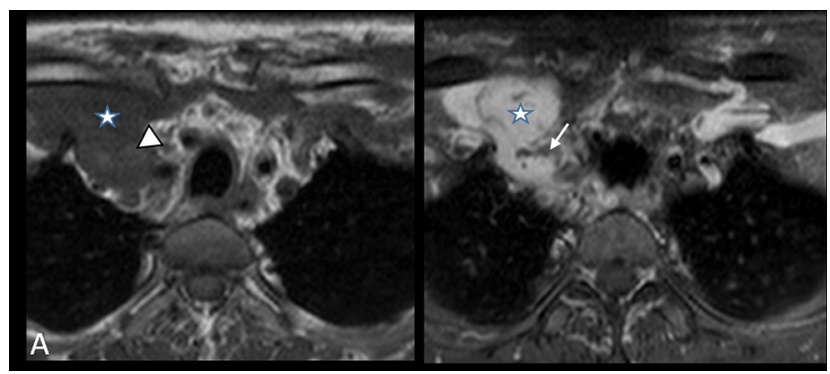

Fig. 3 Contrast-enhanced magnetic resonance imaging with venography. Axial precontrast T1 image (A) and postcontrast T1 (B) image show intensely enhancing mass lesion $\left({ }^{*}\right)$ arising from the right internal jugular vein. Nonenhancing filling defect suggestive of thrombus is seen in the rest of the compressed lumen on the contrast image (arrow) that appears hyperintense on the plain image (arrowhead).

of the right internal jugular vein, bilateral brachiocephalic vein, and superior vena cava. Confluence of right subclavian and right internal jugular vein was not separately identified from the mass lesion. Multiple superficial venous collaterals were seen over the right neck and chest region (-Fig. 4). Exophytic component was seen extending into the right supraclavicular fossa; however, no evidence of any soft tissue or bony invasion was noted. Ultrasound-guided biopsy was done from the exophytic component that revealed clusters of pleomorphic spindle cells showing Bcl-2 vimentin and FLI 1 positivity suggesting SFT ( - Fig. 5). Based on the radiological and histopathological findings, a diagnosis of SFT arising

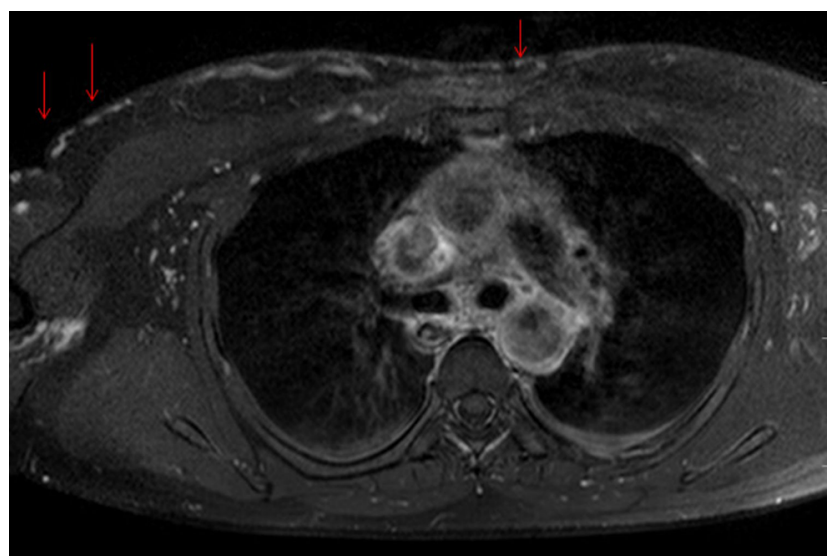

Fig. 4 Contrast-enhanced magnetic resonance imaging shows multiple chest wall collaterals predominantly on the right side (red arrows).

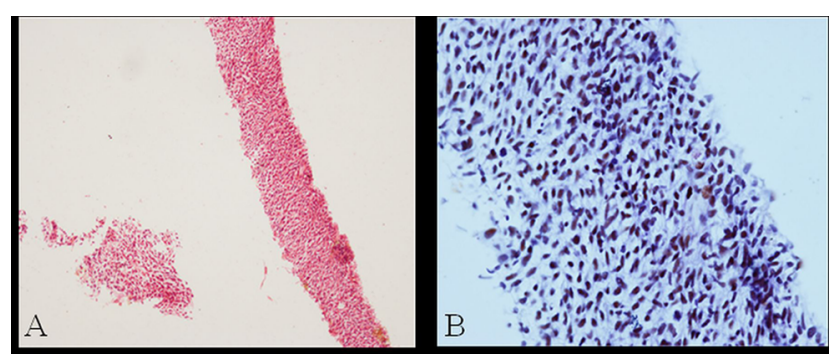

Fig. 5 Histology and immunohistochemistry. (A) Micrograph showing diffuse spindle cell proliferation (hematoxylin and eosin $\times 10$ ). (B) Micrograph showing nuclear Fli-1 positivity in spindle cells (immunohistochemistry Fli $1 \times 20$ ).

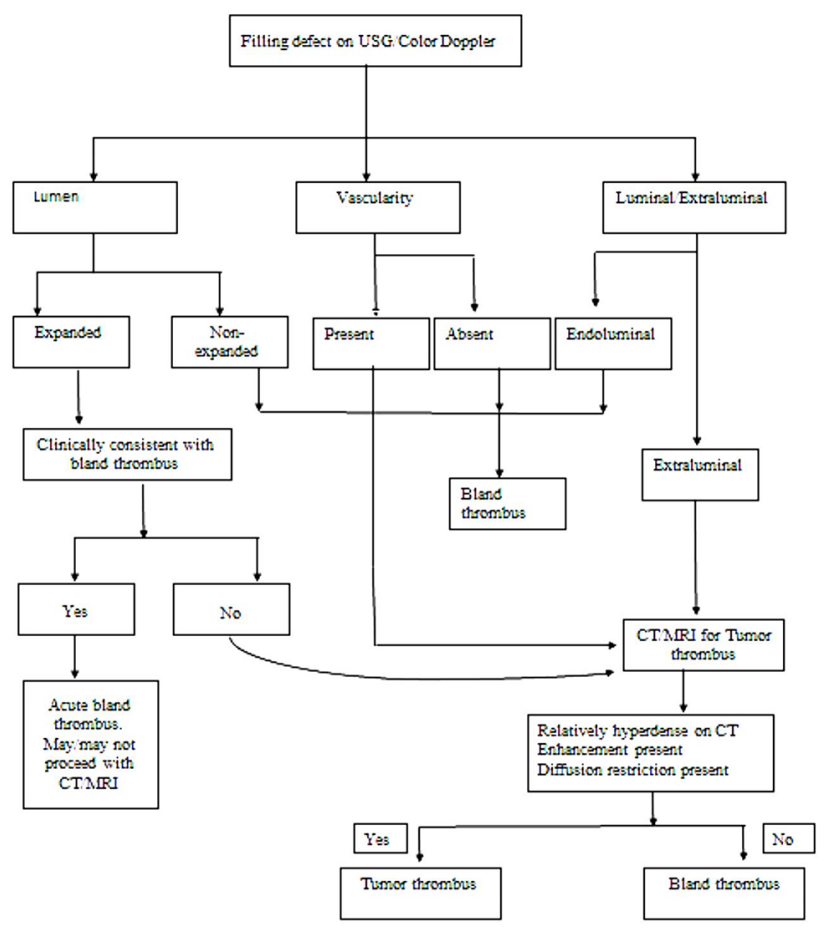

Fig. 6 Flowchart highlighting approach to the differentiation between bland and tumoral thrombus. CT, computed tomography; MRI, magnetic resonance imaging; USG, ultrasonography. 
from the right internal jugular vein with extension into the right supraclavicular fossa was made. The patient was started on anticoagulants and referred for radiotherapy. Patient is symptomatically better and is on follow-up on the outpatient department. Follow-up ultrasound Doppler shows mild resolution in the size of mass lesion and thrombus extension.

\section{Discussion}

SFT is an uncommon tumor of mesenchymal origin arising from pleura. ${ }^{3}$ Extrapleural involvement is uncommon but has been observed at almost every anatomic site including orbit, prostate, liver, kidney, pancreas, reproductive system, retroperitoneum, head and neck, pelvis, breast, and soft tissue of extremities. ${ }^{4-6}$ The intravascular SFT is very uncommon. There are case reports in the literature describing SFT arising from IVC and renal vein but no one has reported SFT arising from the internal jugular vein so far. ${ }^{7}$

The clinical symptoms of intravascular SFT can vary from paraneoplastic syndrome of SFT to obstructive symptoms of vascular compression. Venous obstruction is usually seen at advanced staged and can manifest in the form of edema, congestion, and thrombosis. Besides, SFT is known to secrete insulin-like growth factors that lead to hypoglycemia and weight loss. ${ }^{8}$ Our patient presented with symptoms due to luminal obstruction of the right internal jugular vein.

SFT is usually hypoechoic on ultrasound and shows variable vascularity. Occasionally, it may appear heteroechoic due to myxoid degeneration. Appearance on CT varies from hypodense to hyperdense depending upon the collagen content, with high collagen tumor appearing hyperdense and vice versa. Heterogeneous enhancement is seen on contrast administration in $60 \%$ of benign and $100 \%$ of malignant tumors. On MRI, it appears isointense on $\mathrm{T} 1$ and heterointense on T2 images. Round or linear T1 and $\mathrm{T} 2$ hypointense foci are attributable to the collagen content. The combination of these features is commonly called a chip cookie appearance. On contrast administration, it produces vigorous enhancement., ${ }^{9,10}$ Associated bland thrombus with the tumoral thrombus is also seen that is secondary to stasis, hypercoagulability, turbulence, and thrombus propagation. ${ }^{11}$

The diagnosis of intravascular SFT is very challenging for imaging. Several benign and malignant vascular neoplasms share similar imaging features. The differentials of primary vein lesions are bland thrombus, leiomyoma, and leiomyosarcoma. The secondary venous tumors are a direct extension of tumor into the vein and thromboembolism from the malignancy. ${ }^{12-14} \mathrm{CT}$ and MRI are reliable techniques in differentiating these entities. The features like lumen expansion, exophytic component, contrast enhancement, and diffusion restriction favor intraluminal mass over bland thrombus. Approach to the differentiation between bland and tumoral thrombus is highlighted in the flowchart (-Fig. 6). The next diagnostic conundrum is to establish the vascular origin of neoplasm from a locoregional mass, more so in cases of pliable veins. Webb et al have proposed imperceptible IVC sign on CT imaging, differentiating IVC leiomyosarcoma from retroperitoneal mass with IVC invasion. This proposed sign is equivalent to "phantom (invisible) organ sign" that shows imperceptible vein (IVC) at the site of maximum contact with mass. Nonvascular origin of the mass shows a negative embedded sign, that is, vessel compressed at the periphery in the form of a crescent. Other CT signs described for vascular origin of mass were positive embedded sign (vein is embedded in the periphery of mass) and luminal tumor (invasion of IVC lumen). They concluded that imperceptible vein sign has a positive predictive value $100 \%$, for the origin mass from the IVC and a negative embedded organ sign was most useful for excluding IVC origin. ${ }^{15}$

Final diagnosis is made on biopsy and histopathological examination. Histologically, the SFT shows a patternless appearance with alternating hyper and hypocellular areas of spindle-shaped cells. On immunohistochemistry, tumor cells are positive for $\mathrm{CD} 34, \mathrm{CD} 99, \mathrm{Bcl} 2$, vimentin and negative for S-100 and desmin. ${ }^{16}$ Histopathology in our case revealed a cluster of pleomorphic spindle cells that showed positivity for FL1, Bcl-2, and vimentin on immunohistochemical staining.

Surgical resection is the most appropriate and definitive treatment. Metastasis is seen with SFT. The common sites of metastasis are liver, lung, and vertebra. ${ }^{17}$ Chemotherapy and radiotherapy are reserved for patients with unresectable and metastatic disease. ${ }^{18}$ Our patient was referred for radiotherapy and is on follow-up in the outpatient department.

In summary, intravascular SFTs are extremely rare neoplasm and present with vascular obstructive features. There are no specific imaging features and common mimickers include phlebothrombosis, leiomyoma, and leiomyosarcoma. As far as the vascular SFT is concerned, there are case reports of SFT involving IVC and renal vein, but this is the first case report of SFT involving internal jugular vein. We conclude that SFT of internal jugular vein is a very rare tumor and must be included in the differentials with similar imaging findings.

\section{Financial Support and Sponsorship}

Nil.

\section{Conflicts of Interest}

There are no conflicts of interest.

\section{References}

1 Klemperer P, Rabin CB. Primary neoplasms of the pleura. A report of five cases. Arch Pathol (Chic 1931;11:385-412

2 Robinson LA. Solitary fibrous tumor of the pleura. Cancer Contr 2006;13(4):264-269

3 Briselli M, Mark EJ, Dickersin GR. Solitary fibrous tumors of the pleura: eight new cases and review of 360 cases in the literature. Cancer 1981;47(11):2678-2689

4 Changku J, Shaohua S, Zhicheng Z, Shusen Z. Solitary fibrous tumor of the liver: retrospective study of reported cases. Cancer Invest 2006;24(2):132-135

5 Fine SW, McCarthy DM, Chan TY, Epstein JI, Argani P. Malignant solitary fibrous tumor of the kidney: report of a case and comprehensive review of the literature. Arch Pathol Lab Med 2006;130(6):857-861 
6 Zhou Y, Chu X, Yi Y, Tong L, Dai Y. Malignant solitary fibrous tumor in retroperitoneum: a case report and literature review. Medicine (Baltimore 2017;96(11):e6373

7 Koh SZ, Tiong HY, Wang S, Madhavan K. A case report of an intracaval extrathoracic solitary fibrous tumour. Ann R Coll Surg Engl 2013;95(4):e71-e74

8 de Perrot M, Kurt AM, Robert JH, Borisch B, Spiliopoulos A. Clinical behavior of solitary fibrous tumors of the pleura. Ann Thorac Surg 1999;67(5):1456-1459

9 Rosado-de-Christenson ML, Abbott GF, McAdams HP, Franks TJ, Galvin JR. From the archives of the AFIP: localized fibrous tumor of the pleura. Radiographics 2003;23(3):759-783

10 Weon YC, Kim EY, Kim HJ, Byun HS, Park K, Kim JH. Intracranial solitary fibrous tumors: imaging findings in 6 consecutive patients. AJNR Am J Neuroradiol 2007;28(8):1466-1469

11 Rohatgi S, Howard SA, Tirumani SH, Ramaiya $\mathrm{NH}$, Krajewski KM. Multimodality imaging of tumour thrombus. Can Assoc Radiol J 2015;66(2):121-129

12 de Chaumont A, Pierret C, de Kerangal X, Le Moulec S, Laborde F. Leiomyosarcoma of the superior vena cava. Ann Thorac Surg 2014;98(2):725-727
13 Klunder A, Subik K, Ye B, Xu H, Li F. Intimal sarcoma of the abdominal aorta presenting as a retroperitoneal mass. Pathology 2012;44(5):485-487

$14 \mathrm{Hu} \mathrm{W}$, Wang X, Tan S, et al. Large hemangioma in a persistent left superior vena cava. Thorac Cardiovasc Surg 2012;60(Suppl 2):e3-e5

15 Webb EM, Wang ZJ, Westphalen AC, Nakakura EK, Coakley FV, Yeh BM. Can CT features differentiate between inferior vena cava leiomyosarcomas and primary retroperitoneal masses? AJR Am J Roentgenol 2013;200(1):205-209

16 Vogels RJ, Vlenterie M, Versleijen-Jonkers YM, et al. Solitary fibrous tumor - clinicopathologic, immunohistochemical and molecular analysis of 28 cases. Diagn Pathol 2014;9:224

17 Tamburini N, Fabbri N, Anania G, et al. Synchronous pancreatic and pulmonary metastases from solitary fibrous tumor of the pleura: report of a case. Tumori 2017;103(Suppl 1):e9-e11

18 DeVito N, Henderson E, Han G, et al. Clinical characteristics and outcomes for solitary fibrous tumor ( $\mathrm{Sft}$ ): a single center experience. PLoS One 2015;10(10):e0140362 